(3) It shows the decomposition of nitro-compounds other than nitrocellulose which are often present in a finished powder, and it also shows the effect of this decomposition on the powder itself.

(4) It shows the effect on the stability of a powder, of small quantities of added substances (for masking stability or other purposes); volatile matter; handling and working which may set up local decomposition; traces of nitrating acids due to imperfect purification; decomposition due to saponification ${ }^{1}$ by water, alkalies, carbonates, etc.

(5) It shows quantitatively the progress of all decomposition.

(6) The test itself, as well as the apparatus, is simple and not subject to variations like the old tests.

CHEMICAL LAHORATORY. FRAYKFORD ARSENAL, PhILADELPHiA.

\title{
A STUDY OF THE DOUBLE CYANIDES OF ZINC WITH POTASSIUM AND WITH SODIUM.
}

BY W. J. SHARWOOD.

Received March $3^{\circ}$, rgO3 $^{2}$

DURING the precipitation of gold and silver by means of metallic zinc, from the solutions obtained in the cyanide process of extracting precious metals from their ores, more or less zinc is dissolved and accumulates to a certain extent in these solutions, and its presence in some instances modifies or complicates the estimation of the simple alkaline cyanide in such solutions, and also slightly affects their subsequent action on some of the constituents of the ores or other materials treated by them.

A typical solution might have originally contained one-fourth of I per cent. of potassium cyanide, to which about the same amount of calcium hydroxide or sodium hydroxide might be added, after which, with occasional additions of the same reagents, it has been filtered alternately through pulverized ore and finely divided metallic zinc, several tenths of a per cent. of which might be found in the final solution. Some discussion has arisen as to the forms in which the zinc and cyanogen may be distributed in such a solution, whether, for instance, the zinc is in the form of a zincate $\left(\mathrm{K}_{2} \mathrm{ZnO}_{2}\right)$ or a double cyanide $\left(\mathrm{K}_{2} \mathrm{ZnCy}_{4}\right)$. The latter opinion has been more generally favored, but after a cyanide solution has been in use for some months-judging from the published analyses

1 Thomas: Zischr. angew. Chem.. (işৎ9), p. 55. 
of others as well as those made by the writer-the zinc will usually be found considerably in excess of the ratio of I atom zinc to 4 equivalents of cyanogen, that is, of the cyanogen contained in simple alkaline cyanides plus that in the double zinc cyanide, although the solution may still have an excellent solvent action on the precious metals and may still show the same percentage of "available" cyanogen by the usual methods of titration with silver nitrate, which was formerly supposed to indicate only that portion of the potassium cyanide which was uncombined with zinc and so available as a gold solvent.

A. James ${ }^{1}$ proved that when equivalent weights of crystallized potassium zinc cyanide and caustic potash were mixed and evaporated, the crystals deposited were still almost pure double zinc cyanide and contained practically all the cyanogen present, and that the same compound separated out when potassium zincate was mixed with a potassium cyanide solution and evaporated. The writer has confirmed these results, and also found that almost any compound of zinc, dissolved in almost any proportion in potassium cyanide, will similarly deposit crystals of potassium zinc cyanide, proving that, in saturated solutions, this is the compound which tends to form, whether by virtue of greater stability or lesser solubility. In the dilute solutions met with in metallurgical work the conditions may be different, but it is difficult to prove, for instance, in a solution containing potassium, zinc, and cyanogen in the proportions corresponding to $6 \mathrm{~K}+\mathrm{Zn}+4 \mathrm{Cy}$, whether it actually contains $\mathrm{K}_{2} \mathrm{ZnO}_{2}+{ }_{4} \mathrm{KCy}$ or $\mathrm{K}_{2} \mathrm{ZnCy}_{4}+$ $4 \mathrm{KOH}$, as the results of titration or of gravimetric analysis would be the same in either case, and there seems to be no direct method of settling the question.

Some attempts were therefore made to decide this point by indirect means, to investigate more thoroughly the reactions which take place when various zinc compounds are dissolved in solutions of alkaline cyanides, or zinc cyanide in caustic alkalies, and to determine whether there is any appreciable difference in the effects of sodium and of potassium compounds in this direction, as might be inferred from the different constitutions assigned by Rammelsberg $\left(\mathrm{K}_{2} \mathrm{ZnCy}_{4}\right.$ and $\left.\mathrm{NaZnCy}_{3}\right)$ to the double cyanides of zinc with these metals. The results of the work in

iJ Soc. Chem. Ind, 16, 120 (1897). 
this connection on the solvent action of zinc potassium cyanide solutions on gold have been already published. ${ }^{1}$

METHODS OF ANALYSIS.

In the analyses necessary for this investigation the only determinations required were those of zinc, cyanogen, and alkali, carbonate being the only impurity present in quantity. In the crystals examined, water and alkali-metal were also weighed.

Water was estimated by heating the crystals to $10^{\circ} \mathrm{C}$. until constant weight was attained.

Zinc was determined by decomposing with hydrochloric acid, heating to expel any hydrocyanic acid present, neutralizing with sodium hydroxide, then adding a constant quantity ( $3 \mathrm{cc}$.) of strong hydrochloric acid, diluting to 150 or $200 \mathrm{cc}$. and titrating with a weak solution of potassium ferrocyanide, using uranium acetate as indicator, the titration being carried out in a hot solution, and a correction $(0.3 \mathrm{cc}$.) being deducted for the quantity necessary to color the indicator.

Cyanogen was estimated by dissolving in or adding ammonia, and titrating with standard silver nitrate, using potassium iodide as an indicator. When zinc was present, an excess of sodium hydroxide was also added, and when present in proportions approaching $\mathrm{Zn}: 4 \mathrm{Cy}$ an addition of one part in 200 was made to the cyanogen found by titration, that correction having been found necessary by previous experiments.

Alkali (potassium or sodium cyanide or hydroxide) was titrated by standard sulphuric acid, using phenolphthalein as an indicator, or, in some cases, methyl orange. In most instances, excepting the earlier experiments, carbonates had been removed from the solutions by means of lime, and, when the alkalinity of simple alkali-metal cyanide was found to exceed that due to the cyanogen present, the slight excess of alkali was usually neutralized by addition of standard acid in small quantity.

Sodium and potassium were gravimetrically determined, in some instances, as sulphates.

The probable composition of the solutions was calculated as follows: If the zinc present exceeded the ratio $\mathrm{Zn}: 4 \mathrm{Cy}$ all cyanogen was reckoned as $\mathrm{K}_{2} \mathrm{ZnCy}_{4}$, the remaining zinc as $\mathrm{K}_{2} \mathrm{ZnO}_{2}$, and residual potassium as $\mathrm{KOH}$. If the zinc present were below the amount corresponding to the ratio $\mathrm{Zn}: 4 \mathrm{Cy}$, zinc was reckoned as $\mathrm{K}_{2} \mathrm{ZnCy}_{4}$,

1 Eng. and Win. J. 64, 396, 426, 460 
the remaining cyanogen as $\mathrm{KCy}$, and residual potassium as $\mathrm{KOH}$. In the few cases in which zinc was in excess of the ratio $\mathrm{Zn}: 2 \mathrm{~K}$, the excess of zinc was calculated as $\mathrm{ZnCy}_{2}$ and the remainder as $\mathrm{K}_{2} \mathrm{ZnCy}_{4}$ and $\mathrm{K}_{2} \mathrm{ZnO}_{2}$.

\section{PREPARATION OF ZINC CYANIDE.}

The standard methods recommended for its preparation are the precipitation of a zinc salt in solution by means of potassium cyanide (any carbonate in which coprecipitates zinc carbonate), and passing hydrocyanic acid into a solution of zinc acetate, when zinc cyanide separates. Special precautions are said to be necessary. ${ }^{1}$

According to Gmelin's "Handbook" the cyanide precipitated by the first method contains:

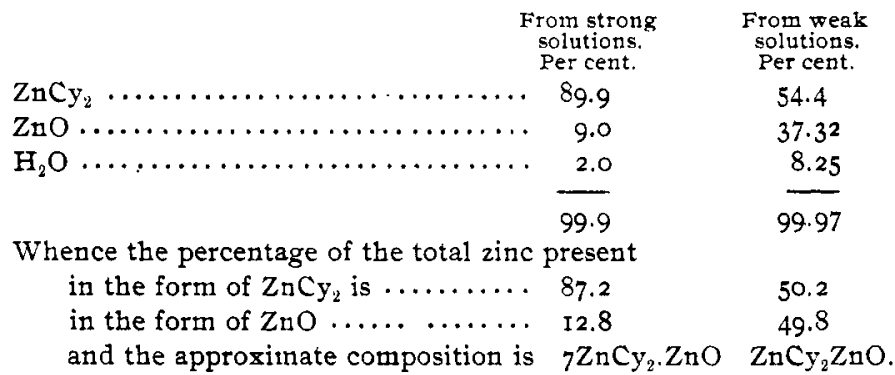

Two attempts were made to prepare zinc cyanide by passing hydrocyanic acid into zinc acetate solution, but the amount of precipitate obtained was relatively small, and action seemed to cease at an early stage, presumably owing to the acetic acid set free preventing further action by the hydrocyanic acid, or redissolving the precipitate.

A Io per cent. solution of purified zinc sulphate crystals was then precipitated by a 5 per cent. solution of " 98 per cent. potassium cyanide" containing also sodium cyanide and carbonate, the zinc being kept in slight excess; the precipitate was washed free from sulphate. It was found to consist of a mixture of zinc cyanide with some zinc carbonate and a large proportion of zinc oxide or hydroxide.

1 Gmelin's "Handbook," (1854 ed.), Vol. VII, p. 422; Corriol and Berthemot: J. Pharm., 16, 444; Br. Arch., 35, 153; Repert, 36, 106; Bette: Ann. Pharm., 31, 214; Henry: J. Pharm., 15, 57 ; Schindler: Mag. Pharm., 36, 67; wittstein : Repert, 63, 314; Rammelsberg: Pogg. Ann., 42, II4 ; Joanuis : Compt. Rend., 92, 1338, 1417; Wohler: Berz. Jokrest., 20, 152 ; Oppermann : Jahresb. d. Chemie (1860), p. 226; Varet: Compt. rend., 105, 170; Ann.chim. phys., [7], 105 (1897). 
A second lot was similarly prepared, but the cyanide was first carefully freed from carbonate by means of lime, and freshly boiled distilled water was used in dissolving and washing. This precipitate was found practically free from carbonate but only 58 per cent. of the zinc present was in the form of $\mathrm{ZnCy}_{2}$, the remaincler being presumably oxide or hycroxicle. A third precipitation gave 55 per cent. of the zinc in the form of cyanide. In these and several other experiments it was found that the zinc cyanicle lost cyanogen on washing, becoming more and more basic, ${ }^{1}$ the wash-water smelling of hylrocyanic acid: after long washing, the zinc in the form of $\mathrm{ZnCy}_{\mathrm{n}}$ approximated 50 per cent, of the total zinc present, indicating the composition $\mathrm{ZnO} \mathrm{ZnCY}_{2}$. This can be rapidly estimated by shaking up the precipitate, taking out two equal portions of the emulsion with a pipette $(2 \mathrm{cc}$. if thick, or proportionately more if much water is present) and estimating zinc in one and cyanogen in the other by titration with ferrocyanide and silver nitrate respectively.

It is difficult to wash freshly precipitated zinc cyanide; it settles very slowly in water and will pass through any filter-paper; this nay be remedied to some extent by adding about 5 per cent. of sodium sulphate to the first wash-waters, after which it settles fairly well, so that the water can mostly be decanted or siphoned off after five or ten minutes' standing.

(in attempting to dry the precipitate there is always some clecomposition, ammonia being formed for one thing; on allowing it to stand in the moist state, some ammonia is also developed.

The best results in preparation were obtained by first roughly precipitating a quantity of zinc cyanide by acting on zinc sulphate with carbonate-free alkaline cyanide; then adding to the roughly washed precipitate more alkaline cyanide-slightly in excess of the amount required to redissolve it. The resulting double cyanide solution was filtered clear, titrated to determine the amount of acid necessary to decompose the alkaline cyanide and liberate $\mathrm{ZnCy}_{2}$, and then the whole was decomposed by a slight excess of sulphurc acid, added with constant stirring. The precipitation must be carried on in a good draft to avoid trouble with the hydrocyanic acid evolved. The vessel was then covered and allowed to stand till most of the precipitate had settled: the

1 Although the reaction $7 \mathrm{nCy}_{\mathrm{O}}+\mathrm{H}_{2} \mathrm{O}=\mathrm{ZnO}+2 \mathrm{HCy}$ (dissolved) is said to ahsorb I to 16 heat units. 
bulk of the clear liquor was poured off and the precipitate washed several times with water, the first one or two lots containing a little free acid. This insures the evolution or presence of some hydrocyanic acid and counteracts the tendency of the water to hydrolyze the cyanide and render it basic. In one case, the washing was conducted with a solution of hydrocyanic acid.

Prepared in this way the proportion, by weight, of zinc to cyanogen is almost exactly $5: 4$, or practically all the zinc is in the form of cyanide. The product thus obtained, kept as an emulsion, is alluded to as "pure zinc cyanide"; that obtained in earlier tests and approaching the composition $\mathrm{ZnO} . \mathrm{ZnCy}_{2}$ as "basic zinc cyanide."

PREPARATION OF PURE CRYSTALIIZED POTASSIUM ZINC CYANIDE,

$$
\mathrm{K}_{2} \mathrm{ZnCy}_{4} \text {. }
$$

This salt crystallizes readily in regular octahedra, and was easily prepared in solution by several methods. ${ }^{1}$ It was obtained in a nearly pure form by first precipitating an impure basic cyanide by treating zinc sulphate with commercial "98 per cent." cyanide, containing about one-third sodium and two-thirds potassium cyanide, adding to the washed precipitate enough of the same cyanide in a hot solution to nearly redissolve it, filtering, cooling and allowing to crystallize, then recrystallizing the product three times by rapidly cooling a hot solution. The small crystals formed were thrown on a filter and sucked dry by a vacuum pump, washed twice with cold water and sucked dry; finally they were dried on filter-paper and kept some days over sulphuric acid. Water was estimated by drying at $110^{\circ} \mathrm{C}$. to constant weight; on further heating there was no appreciable loss short of fusion. No sodium was detected.

\begin{tabular}{|c|c|c|c|c|c|c|}
\hline & \multirow{2}{*}{$\begin{array}{l}\text { Calculated for } \\
\mathrm{K}_{2} Z n C y_{4} \cdot \\
\text { Per cent. }\end{array}$} & \multicolumn{4}{|c|}{ Found. } & \multirow{2}{*}{$\begin{array}{l}\text { Aver- } \\
\text { age. }\end{array}$} \\
\hline & & I. & II. & III. & IV. & \\
\hline Potassium.... & $3 I .56$ & 31.49 & $\ldots$ & $\ldots$ & $\cdots$ & 31.49 \\
\hline Zinc ... & 26.39 & 26.16 & 26.16 & 26.32 & $\ldots$ & 26.22 \\
\hline Cyanogen .... & 42.05 & 41.88 & 41.88 & $4 \mathrm{I} .77$ & $4 I .77$ & $4 I .82$ \\
\hline Water ....... & 0.00 & 0.20 & $\cdots$ & $\cdots$ & $\cdots$ & 0.20 \\
\hline
\end{tabular}

The composition found by analysis, therefore, agrees precisely with

1 Gmelin's "Handbook," Vol. VII, p. 422; Rammelsberg : Pogg. Ann, 42, II2 (197); Fresenius and Haidlin : Ann. Chem. (Liebig), 43, 132; Sharwood : Eng. Min.J., October 9. I897; Schiodler: Mag. Pharm., 36, 67. 
the percentage composition calculated from the formula assigned by Rammelsberg, whose determinations for zinc varied from 25.25 to 26.379 .

\section{SOLUBILITY.}

This salt is stated in Comey's "Dictionary" to be "easily soluble in cold water." The mean of three cleterminations on the crystals above described gave a solubility of almost exactly I grams of potassium zinc cyanide in $100 \mathrm{cc}$. of water at a temperature of $20^{\circ} \mathrm{C}$., but there is some tendency to form supersaturated solutions, and at higher temperatures the solubility is considerablv greater. Only a minute trace was found to be dissolved by 100 cc. ethyl alcohol of specific gravity 0.798 (99 per cent.) at $20^{\circ} \mathrm{C}$. In wood spirit, turpentine, ether, chloroform, acetone, carbon disulphide, coal oil and gasoline it was found to he completely insoluble.

On boiling a dilute water solution of this salt it is not precipitated, and carbonic acid is almost without effect upon the solution.

SODIUM ZINC CYANIDFs, $\mathrm{Na}_{2} \mathrm{ZnCY}$, and NaZnCy:; $+21 / 2 \mathrm{H}_{2}()^{1}$

The only reference found to the double sodium-zinc cyanide was that of Rammelsberg," also quoted by Gmelin's "Handbook," Vol. VII, p. 422.

Rammelsberg sars, in effect: "It was prepared in the same way" as the potassium salt (acting on zinc cyanide) by means of sodium cyanide. The latter was obtained by saturation of pure (strong) hycirocyanic acid with lime, and decomposition of the calcium cyanide with sodium carbonate. The solution of the double zinc (sodium) cyanide leaves first, on strong concentration, glittering white leaflets, the precise form of which conld not be leterminer The properties of this salt are in general those of potassium zinc cyanide, but it is very readily soluble in water, and holds water combined; this, however, it loses, as it seems completely, at $200^{\circ}$ C. The loss of weight in two analyses shows $21.7 \mathrm{I}$ and 2.3 .88 per cent.

"Analysis of the clesiccated salt shows:

(I) $0.45^{8}$ gram gave $\mathrm{ZnO} 0.2194=\mathrm{ZnO} 0.17584 ; \mathrm{Na}_{2} \mathrm{SO}_{4} 0.2 \mathrm{r}=\mathrm{Na} 0.068478$.

(2) 0.5 I gram gave $\mathrm{ZnSO}_{4} 0.475=Z \mathrm{Zn} 0.190695 ; \mathrm{Na}_{2} \mathrm{SO}_{4} 0.26=\mathrm{Na} 0.08478$.

1 In Morley and Muir's edition of Watts' "Dictionary." this formula is incorrectly quoted as $\mathrm{NaZnCy} \cdot 5 \mathrm{H}_{2} \mathrm{O}$.

2 Pogg. Ann, 42, I12 (.83i). 
Whence the percentage is:

\begin{tabular}{|c|c|c|c|c|}
\hline \multirow[b]{2}{*}{ 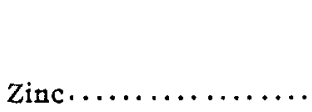 } & \multicolumn{2}{|c|}{$\begin{array}{c}\text { Observed by } \\
\text { Rammelsberg. }\end{array}$} & \multirow{2}{*}{$\begin{array}{c}\text { Calculated for } \\
\text { NaznCy by } \\
\text { Rammelsberg. } \\
38.65\end{array}$} & \multirow{2}{*}{$\begin{array}{l}\text { Recalculated } \\
\text { for NaZnCy }{ }^{1} \\
39.26\end{array}$} \\
\hline & 38.393 & 37.391 & & \\
\hline Sodium............ & I 4.95 I & 14.624 & I $3.93^{8}$ & $\mathrm{I} 3.84$ \\
\hline Cyanogen ........... & not est & nated & 47.422 & 46.9 \\
\hline Cyanogen by difference & 656 & $\left(47.9^{8} 5\right)$ & To... & $\ddot{100.0}$ \\
\hline
\end{tabular}

Or a compound of 2 equivalents zinc cyanide with I equivalent of sodum cyanide, with which 5 equivalents of water ( $\mathrm{HO}$ in old atomic weights, i. e., 2.5 molecules $\mathrm{H}_{2} \mathrm{O}$ in new system) appear to be combined, which would make $2 \mathrm{I} .23$ per cent. water. The discrepancy between the found and calculated results lies doubtless in a small admixture of sodium carbonate which was always mixed with the salts examined."

ATTEMPTS AT PREPARATION OF SODIUM ZINC CYANIDE.

I made several preliminary attempts to obtain this salt by dissolving precipitated zinc cyanide, first in solutions prepared from the "purest" sodium cyanide on the market, and then with a solution of caustic soda saturated with HCN. The only crystals obtained were filmy flakes, left when the solutions had been evaporated to a thick syrup by standing several weeks in desiccators over sulphuric acid.

Larger quantities of a stronger solution were then prepared but these refused to crystallize at all until some of the flakes previously obtained were dropped in; this induced a slow deposition of similar leaf-like crystals, several grams of which were finally obtained, and dried by pressing between filter-paper. Analyses of these are given below as Samples A and B. On attempting to redissolve these in a little water, so as to recrystallize and purify them, they decomposed to some extent, an insoluble basic cyanide of zinc separating ont in small quantity; the new solution could not be induced to crystallize. It was impossible to free them completely from the mother-liquor, which was so concentrated as to affect the analysis seriously.

Another solution was similarly prepared and allowed to stand over sulphuric acid for over a month without yielding any crystals; it was then left out of doors two days in severely cold weather; the temperature ranging from $0^{\circ}$ to $-35^{\circ} \mathrm{C}$, when some large

I W. J. S.: F. W. Clarke's atomic weights. 
tabular crystals were formed; these, however, turned out to consist chiefly of sodium carbonate with 56 per cent. of water, and further crops had a similar composition.

A larger quantity of sodium cyanide was obtained and similarly saturated with zinc cyanide, after removing all traces of carbon dioxide. After very long evaporation a number of octahedral crystals were found which yielded, by analysis, zinc, 27 per cent., cyanogen, 42.8 per cent., water, I per cent., proportions corresponding closely to those of $\mathrm{K}_{2} \mathrm{ZnCy}_{4}$, which they proved to be, resulting from a small amount of potassium found to have been present in the sodium cyanide used in this preparation.

In the meantime a number of experiments had been made which seemed to indicate the solution of zinc cyanide in practically equal amounts by equivalent quantities of potassium and sodium cyanide. These suggested the existence of the compound $\mathrm{Na}_{2} \mathrm{ZnC}_{4}$ in solution and in fact proved it so far as dilute solutions are concerned.

The ratio of zinc to cyanogen in the mother-liquor, from the first crop of crystals of sodium zinc cyanide, also corresponds to the existence of $\mathrm{Na}_{2} \mathrm{ZnCy}_{4}$ in that concentrated solution. Although the sodium zinc cyanide crystals obtained and analyzed, both in this investigation and by Rammelsberg, were decidedly impure, still the atomic ratio of zinc to cyanogen is so nearly $I: 3$ as to make it almost certain that Rammelsberg's formula, $\mathrm{NaZnCy}_{3}$, is correct. There must, however, remain some uncertainty as to the degree of hydration of this salt, as it very easily loses its water of crystallization. Rammelsberg stated that the water was expelled completely at $200^{\circ} \mathrm{C}$. In my experiments it was found to lose all but 2 per cent. by drying over sulphuric acid in vacuo at about $20^{\circ} \mathrm{C}$; t the greater portion of the water was lost at about $70^{\circ} \mathrm{C}$, and there was only a trifling loss of weight when the material, dried at $110^{\circ}$, was heated to fusion.

The comparison given below of the composition calculated and found for the anhydrous compounds shows a considerable variation in different analyses, but a fair approximation to the atomic ratio $\mathrm{Zn}: 3 \mathrm{Cy}$. 


\begin{tabular}{|c|c|c|c|c|c|c|c|c|}
\hline \multirow[b]{4}{*}{$\mathrm{Na}_{2} \mathrm{ZnCy}_{4}$ calculated } & \multicolumn{4}{|c|}{ Percentage composition. } & & & & \\
\hline & \multirow{2}{*}{$\begin{array}{l}\text { water } \\
\text { in } \\
\text { crys. } \\
\text { tals. }\end{array}$} & \multicolumn{3}{|c|}{ Anhydrous salt. } & \multicolumn{4}{|c|}{ Atomic ratio. } \\
\hline & & $\begin{array}{c}\text { So. } \\
\text { dium. }\end{array}$ & Zinc. & $\begin{array}{l}\text { Cyano- } \\
\text { gen. }\end{array}$ & Water. & $\begin{array}{l}\text { Sodi } \\
\text { um }\end{array}$ & Zine. & $\begin{array}{c}\text { Cyano- } \\
\text { gen. }\end{array}$ \\
\hline & $\ldots$ & $2 I .3$ & 30.3 & 48.3 & $\cdots$ & 2.0 & 1.0 & 4.0 \\
\hline $\mathrm{NaZnCy}_{3}$ calculated & $\ldots$ & 13.84 & 39.26 & 46.9 & $\ldots$ & I.O & I.O & 3.0 \\
\hline ammelsberg crys- & & & & & & & & \\
\hline tals, No. I ...... & 21.7 & I $4.95 \mathrm{I}$ & 38.393 & 46.656 & 62.28 & I.IO & 1.0 & 3.05 \\
\hline $\begin{array}{l}\text { Rammelsberg crys- } \\
\text { tals, No } 2 \ldots . . .\end{array}$ & & & & & & & & \\
\hline W. J. S. sample A, & 22.88 & 14.624 & 37.391 & $47.95^{8}$ & 2.34 & I.II & 1.0 & .3 .22 \\
\hline $\begin{array}{l}\text { dried over } \mathrm{H}_{2} \mathrm{SO}_{4} \\
\text { W. J. S. sample B, }\end{array}$ & 2.0 & 19.3 & 34.2 & 45.8 & $\cdots$ & 1.6 & 1.0 & $3 \cdot 36$ \\
\hline $\begin{array}{l}\text { dried on filter- } \\
\text { paper } \ldots . . . . . . .\end{array}$ & 26.0 & $\cdots$ & 33.8 & 42.57 & $2,4 \mathrm{I}$ & $\cdot \cdot$ & 1.0 & 3.16 \\
\hline $\begin{array}{l}\text { W. J. S. sample C, } \\
\text { second crop...... }\end{array}$ & 23.6 & $\cdots$ & 35.5 & 42.4 & 2.4 & $\cdots$ & I.O & 3.0 \\
\hline Motber-liquor .... & $\cdots$ & $\cdots$ & $\ldots$ & $\cdots$ & .. & $\cdots$ & 1.0 & 4.0 \\
\hline
\end{tabular}

The mother-liquor from crystals in samples $A$ and $B$ was of a syrupy consistency and had a specific gravity of about I.35. One cubic centimeter was found to contain zinc, 205 milligrams, cyanogen, 327 milligrams, corresponding almost exactly to the ratio $\mathrm{Zn}: 4 \mathrm{Cy}$.

If the sodium is calculated to correspond to the ratio $2 \mathrm{Na}: \mathrm{Zn}$ we get I45 milligrams per cubic centimeter, or a total of 677 milligrams in I cc. or 1.35 grams of saturated solution, indicating that this salt, $\mathrm{Na}_{2} \mathrm{ZnCy}_{4}$, is soluble in its own weight of water.

METHOD OF CONDUCTING EXPERIMENTS ON THE ACTION OF POTASSIUM AND SODIUM HYDROXIDE AND CYANIDE UPON ZINC OXIDE AND CYANIDE.

The zinc cyanide was obtained in the form of an emulsion; by shaking this up and removing it with a pipette it was possible to gauge the quantity taken to within about I to $\mathrm{r} .5$ per cent., the material having been previously analyzed and being kept in a stoppered bottle. The zinc oxide was weighed out in most cases. The alkaline cyanide and hydroxide were kept in the form of fifthnormal solutions-double the strength intended for the experiments; except in preliminary experiments, the carbonate present was removed by addition of lime. Any slight excess of alkali in the cyanide solutions, due to hydroxide, was usually neutralized by the addition of standard sulphuric acid, the alkaline sulphate thus formed not interfering with the results. 
In any series of experiments a number of graduated flasks were taken, and with a pipette of half their capacity they were halffilled with the fifth-normal solution of cyanicle or hydroxide of potassium or of sodium. Water was then added to partly fill the remaining half of the flask, then the zinc oxide was added, or the zinc cyanide run in from a pipette in suitable amount; then water was added to fill the vessel to the mark (or slightly above the mark when the solid was added in large excess); the contents were thoroughly shaken, and allowed to stand with occasional shaking for some hours or days, either in the cold or with occasional heating. The contents were finally allowed to settle, and aliquot portions of the clear solution were removed with a pipette for analysis; zinc and cyanogen alone were determined, as it hall been found that no alkali-metal was removed from the solution. In some instances the solutions were filtered off, in order to allow of examining the precipitates.

In the analyses the volumetric solutions were adjusted to some multiple of normal strength, and the weights of alkali-metal, zinc, or cyanogen, were not calculated but are stated as so many atoms, molecules, or equivalents per $100 \mathrm{cc}$. of solvent usecl, the solvent being decinormal in every case. One "atom," "equivalent," etc., as thus used, means the corresponding weight expressed in tenths of milligrams. In the tables, therefore, one can at once read, from the experimental data, the number of atoms of zinc, for instance, which passed into solution in a particular experiment, by the action of 100 molecules of alkaline cyanide or hydroxide.

SOLVFNT ACTIOX ON GOID OF SOLLTIONS OF POIMSSIUAT ZINC CYANIDE.

This is less than that of a solution of simple potassium cyanide containing the same amount, or one-half the amount, of cyanogen in equal volumes.

It is increased by addition of caustic alkali, other conditions remaining the same, and the increase is greatest in those solutions to which oxygen has the freest access.

The considerable increase in solient power observed when caustic potash is added (always providing that oxygen is accessible), coupled with the superior effect of free potassium cyanide, is good evidence that some free potassimm cyanide is formed upon such addition, and therefore that in dilute solutions potassium zinc 
cyanide is partially decomposed by canstic alkali, with formation of simple alkaline cyanide, in accordance with the principles of chemical equilibrium between substances in solution.

ACTION OF DILUTE SOLUTIONS OF ALKALINE HYDROXIDES ON ZINC OXIDE.

This must be considered in connection with the side-reactions involved in the solution of zinc oxide in alkaline cyanides, or of zinc cyanide in alkaline hydroxide solutions, as will be shown later.

Prescott and Wilson ${ }^{1}$ have shown that 8 molecules of potassium hydroxide, in a solution of normal strength, are necessary to precipitate and redissolve I molecule of zinc chloride or other zinc salt, and that 7 molecules of sodium hydroxide produce the same effect. Therefore 6 molecules of potassium hydroxide, or 5 of sodium hydroxide, are the least quantities which, in a normal solution, can dissolve freshly precipitated zinc hydroxide. The solutions must then contain: $\mathrm{K}_{2} \mathrm{ZnO}_{2}+{ }_{4} \mathrm{KOH}$, or $\mathrm{Na}_{2} \mathrm{ZnO}_{2}+$ $3 \mathrm{NaOH}$.

Heating or great dilution decomposed or dissociated these compounds, precipitating zinc oxide, but by cautious addition of acid all the excess of alkali could be neutralized, and alkaline zincate left.

In a more dilute, such as a decinormal, solution I have found the amount of zinc oxide dissolved per unit of alkali very much smaller, especially when a dry oxide is used, but that by careful neutralization the zincate may be left in solution if a very slight amount of free alkali is allowed to remain. The solution, however, is always precipitated on heating unless a considerable excess of free alkali is present.

DECINORMAL SOLUTIONS OF ALKALINE HYDROXIDES WITH ZINC OXIDE.

On leaving an excess of dry, finely divided, zinc oxide in contact with solutions of sodium and potassium hydroxides, both of tenth-normal strength, for several days, during which time they were frequently agitated, the amounts found in solution were as follows :

1 This Journal, 2, 27. 
Potassium hydroxide, decinormal solution:

(I) Cold : 100 molecules potassium hydroxide dissolved 2.I molecules zinc oxide.

(2) Cold: 100 molecules potassium hydroxide dissolved 2.7 molecules zinc oxide.

(3) Heated gently : 100 molecules potassium hydroxide dissolved 2.5 molecules zinc oxide.

Sodium hydroxide, decinormal solution :

(I) Cold : roo molecules sodium hydroxide dissolved 4.5 molecules zinc oxide.

(2) Warmed: 100 molecules sodium hydroxide dissolved 8.3 molecules zinc oxide.

On boiling, either of the above solutions, a slight precipitate was thrown down.

The only importance of these last experimental results is to show how little tendency there is for the alkaline zincates to form in these dilute solutions, and how easily they are decomposed.

ACTION OF DILUTE (DECINORMAL) SOLUTIONS OF POTASSIUM CYANIDE UPON ZINC CYANIDE.

The results are given in Table I. In Nos. I to 4 the potassium cyanide contained some sodium cyanide and a little carbonate; the zinc cyanide was also basic. In Nos. 5 to 9 the zinc cyanide was almost exactly normal, but in 5 to 8 it had been kept several days and may have commenced to decompose with the formation of ammonia compounds.

ACTION OF A DILUTE (DECINORMAL) SOLUTION OF SODIUM CYANIDF LPON ZIXC CYANIDE.

The sodium cyanide used contained a little free alkali, but only traces of other impurities. The zinc cyanide was almost normal and recently prepared: $5 \mathrm{cc}$. of the emulsion contained approximately 19 mol. $\mathrm{ZnCy}_{2}+\mathrm{I}$ mol. $\mathrm{ZnO}$.

The ratio of zinc to cyanogen in the saturated solutions closely approximates $\mathrm{I}$ atom to 4 . The solution appears to have followed very closely the reaction corresponding to $4 \mathrm{NaCy}+\mathrm{ZnCy}_{2}=$ $\mathrm{Na}_{2} \mathrm{ZnCy}_{4}$, and it is, therefore, probable that the salt $\mathrm{Na}_{2} \mathrm{ZnCy}_{4}$, analogous to the corresponding potassium compound, is formed and exists in these dilute solutions. Increasing the proportion of zinc cyanide beyond that indicated in the equation has no appreciable effect, the excess remaining practically unacted upon. 
DOUBLE CYANIDES OF ZINC.

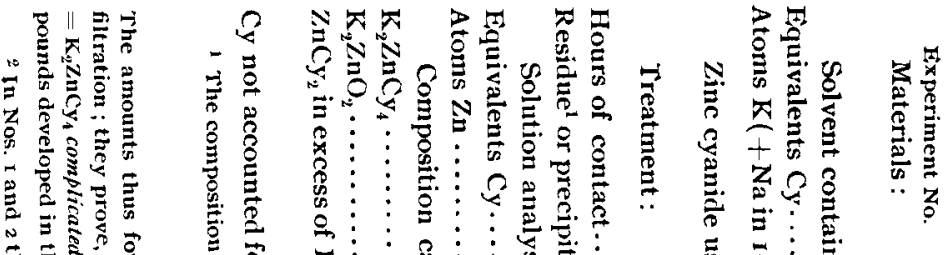

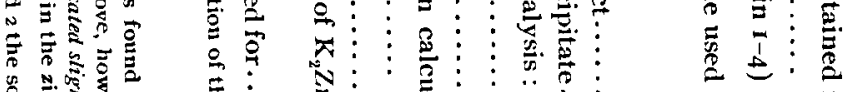

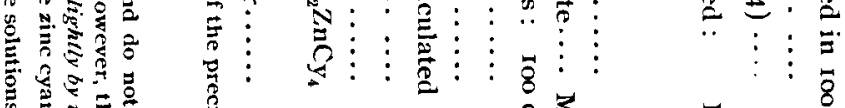

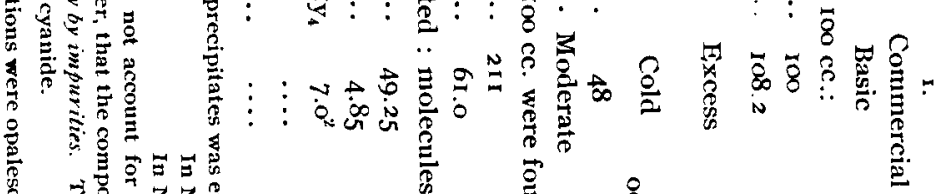

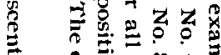

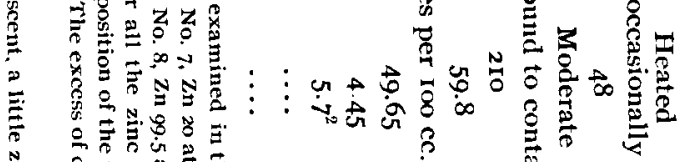

‥

音

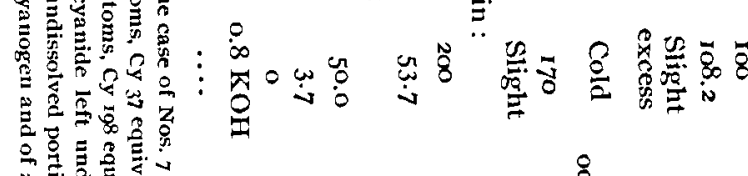

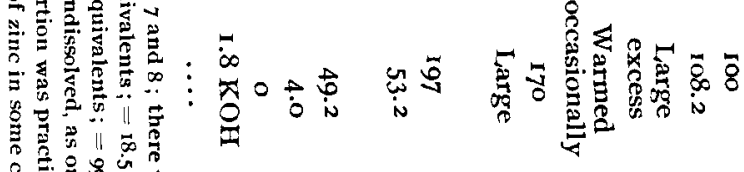

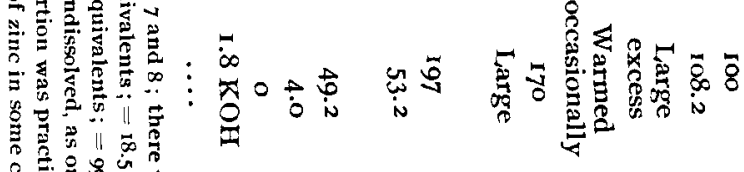

3.

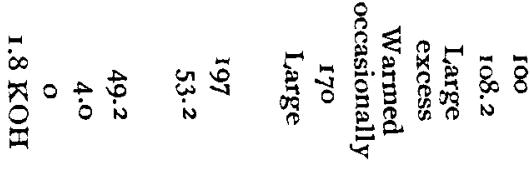

突.

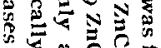

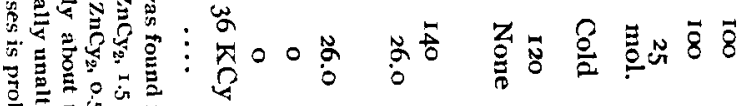

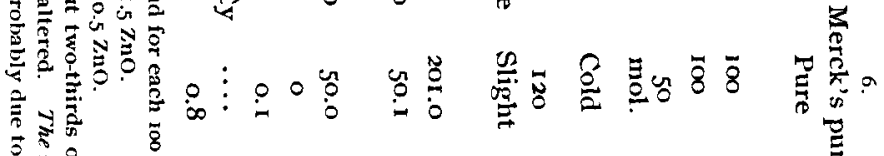

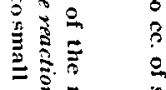

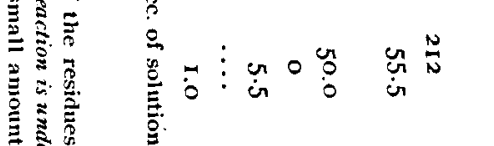

का का

突 
Experiment No.

Solvent contained in $100 \mathrm{cc}$ :

Equivalents $\mathrm{Cy} \ldots \ldots \ldots \ldots \ldots \ldots \ldots$ I00

Atoms $\mathrm{Na} \ldots \ldots \ldots \ldots \ldots \ldots \ldots \ldots \ldots \ldots$

Zinc cyanide used :

Cc. emulsion $\ldots \ldots \ldots \ldots \ldots \ldots \ldots \ldots \ldots$

Molecules $Z_{n} C_{y_{2}} \ldots \ldots \ldots \ldots \ldots \ldots \ldots$ I9.o

Molecules $\mathrm{ZnO} \ldots \ldots \ldots \ldots \ldots \ldots \ldots$ r. 1.0

Hours of contact............. 24.0 t.

I00

$108.3 \quad 108.3$

Solution analysis, found in $\mathrm{r} 0 \mathrm{cc}$ :

Equivalents $\mathrm{Cy} \ldots \ldots \ldots \ldots \ldots \ldots \ldots$

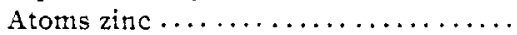

$\begin{array}{lll}\cdots & 200.5 \quad 202.0\end{array}$

Residue

...

50.2

51.0

None Moderate Heavy

Residue analysis, per roo cc. solution ;

Equivalents $\mathrm{C} y \ldots \ldots \ldots \ldots \ldots \ldots \ldots \ldots \ldots \ldots \ldots \ldots \ldots \ldots \ldots$

Atoms $\mathrm{Zn} \ldots \ldots \ldots \ldots \ldots \ldots \ldots \ldots \ldots \ldots$

Composition calculated : molecules per roo cc. of solution

In solution : $\mathrm{Na}_{2} \mathrm{ZnCy}_{4} \ldots \ldots \ldots \ldots \ldots, 20.0 \quad 50 . \mathrm{n} \quad 50.5$

$\mathrm{Na}_{2} \mathrm{ZnO}_{2} \ldots \ldots \ldots \ldots \ldots, \quad 0.0 \quad 0 . \mathrm{I} \quad 0.5$

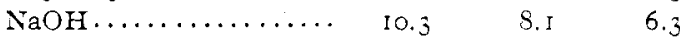

$\mathrm{NaCy}$ in excess $\ldots \ldots \ldots .6 .0 .000$

In residue $: \mathrm{ZnCy}_{2} \ldots \ldots \ldots \ldots \ldots \ldots, 0.0 \quad 4.5 \quad 41.0$

$\mathrm{ZnO} \ldots \ldots \ldots \ldots \ldots \ldots+0.0 \quad 0.0 \quad 1.0$

ACTION OF DILUTE (DECINORMAL) SOLLTIONS OF POTASSIUM CYANIDE UPON ZINC OXIDE.

In all but the first four experments, the results of which are given in Table III, the potassium cyanide solution was free from carbonate, and the small amount of free alkali found was carefully neutralized by addition of standard sulphuric acid. A residue was left in every case but that in No. 7 was excessively small. The residue was tested in several instances, and proved to be zinc oxide holding a mere trace of cyanogen.

Examining the results obtained with cold solutions it will be seen that they all correspond closely to the equation:

$100 \mathrm{KCy}+30 \mathrm{ZnO}+2 \mathrm{OH}_{2} \mathrm{O}=$

or, simplifying,

$$
{ }_{25} \mathrm{~K}_{2} \mathrm{ZnCy}_{4}+5 \mathrm{~K}_{2} \mathrm{ZnO}_{2}+40 \mathrm{KOH}
$$

$$
20 \mathrm{KCy}+6 \mathrm{ZnO}+{ }_{4} \mathrm{H}_{2} \mathrm{O}=5 \mathrm{~K}_{2} \mathrm{ZnCy}_{4}+\mathrm{K}_{2} \mathrm{ZnO}_{2} .8 \mathrm{KOH} ;
$$

that is to say, that the potassium cyanide is apparently completely converted into the double zinc potassium cyanide, with formation of potassium hydroxide, which dissolves a further portion of zinc oxide. After calculating all the cyanogen in solution to $\mathrm{K}_{2} \mathrm{ZnCy}_{4}$, 
DOUBLE CYANIDES OF ZINC.

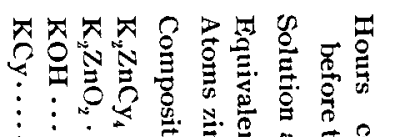

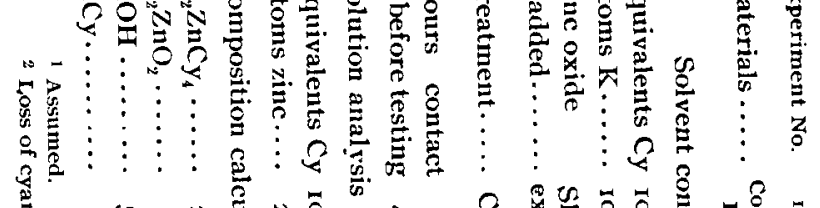

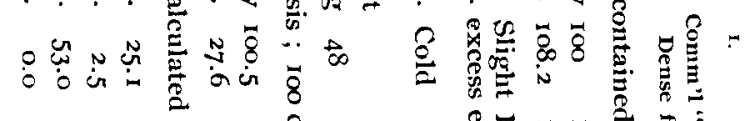

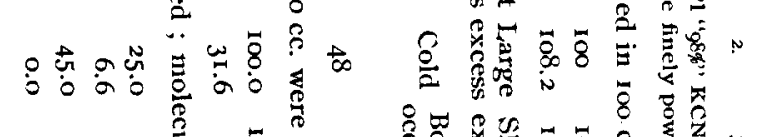

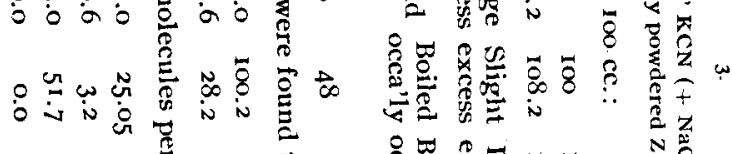

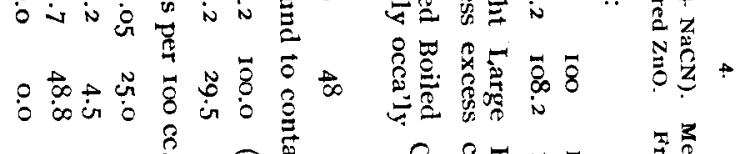

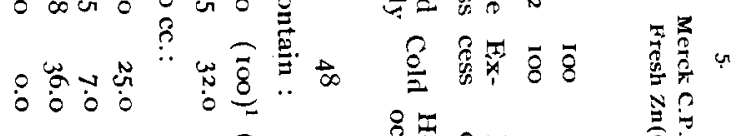

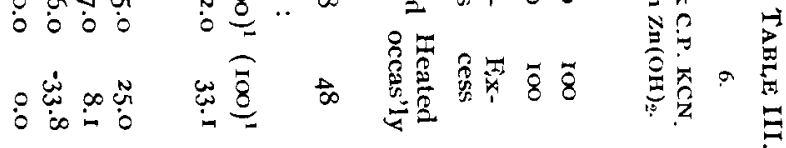

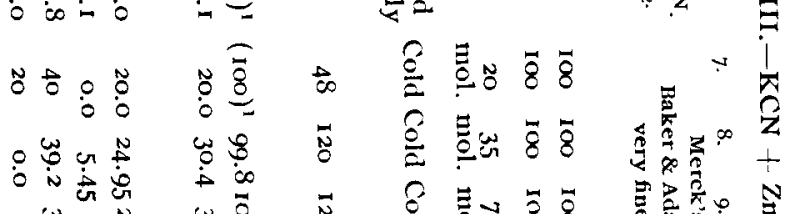

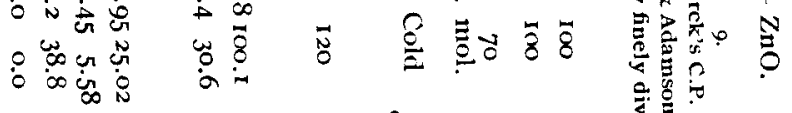

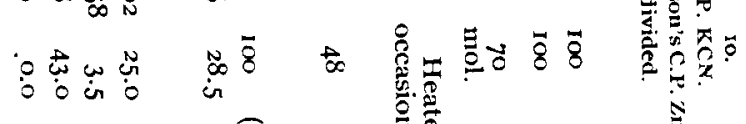

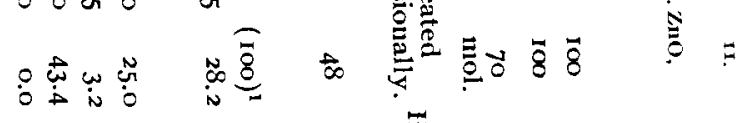

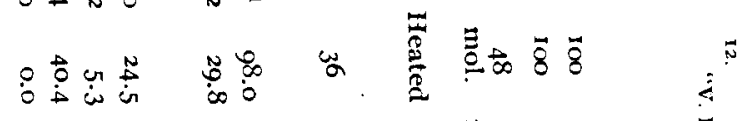

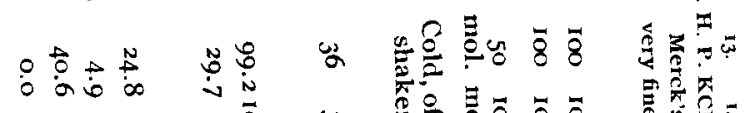

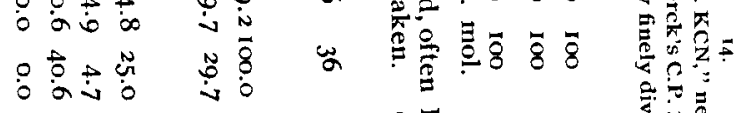

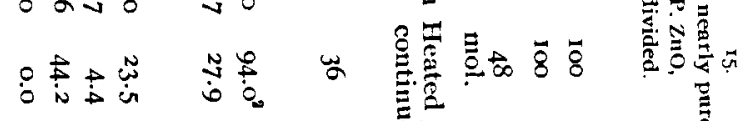

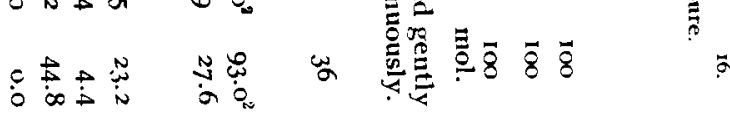


the residual potassium and zinc correspond very closely to the composition $\mathrm{K}_{2} \mathrm{ZnO}_{2} .8 \mathrm{KOH}$, which agrees with the finding of Prescott and Wilson, ${ }^{1}$ that 8 molecules of potash are necessary in a nomal solution to precipitate and redissolve $\mathrm{I}$ molecule of zinc oxide, corresponding to $\mathrm{K}_{2} \mathrm{ZnO}_{2} \cdot 4 \mathrm{KOH}$ in a solution of $110 \mathrm{mmal}$ strength, while a larger cxcess of alkali is required for solution in a weaker solution, such as the decinormal solution used in these experiments.

ACTION OF A DILCTE (DECINORMAL) SOLUITON OF SODILA CYANIDE UPON ZINC OXIDE.

The sodium cyanide used was of the very highest purity, it was freed from carbonates by lime-water, and the slight amount of free alkali remaining was neutralized by standard sulphuric acid. The zinc oxide was Merck's chemically pure, prepared by a dry process, and was very finely divided. Contact was maintained for about thirty-six hours, during the first twenty-four of which the mixtures were frequently shaken.

$$
\text { TABLE IV. }-\mathrm{NaCN}+\mathrm{ZnO} \text {. }
$$

\begin{tabular}{|c|c|c|c|c|c|c|}
\hline Experiment No. & I. & 2. & 3. & 4 & s. & 6. \\
\hline \multicolumn{7}{|c|}{ Solvent contained in $r>0 \mathrm{cc}$ : } \\
\hline Equivalents $\mathrm{Cy} \ldots$. & 100 & IOO & 100 & 100 & 100 & 100 \\
\hline Atoms $\mathrm{Na} \ldots . . .$. & 100 & 100 & 100 & 100 & 100 & 100 \\
\hline \multicolumn{7}{|l|}{ Zinc oxide added in } \\
\hline molecules ...... & 25 & 50 & 75 & 100 & 50 & 100 \\
\hline Treatment $\ldots . .$. & Cold & Cold & Cold & Cold & Warmed & Warm \\
\hline \multicolumn{7}{|c|}{ Found in resulting solution per too $\mathrm{cc}$ : : } \\
\hline Equivalents $\mathrm{Cy} \ldots$... & 100.5 & 100.0 & . & . & 100.0 & 99 \\
\hline Atoms zinc ........ & 23.2 & 30.0 & 30.0 & 30.3 & 28.5 & 28 \\
\hline
\end{tabular}

A residue was left in every case but No. I, in which all but a mere trace of the oxide had dissolved.

From the very close agreement of the ratio between the zinc found in solution and the solvent taken, with the similar ratio observed in the case of potassium cyanide solutions acting on zinc oxide, it is evident that the reactions in the two cases are practically identical. The calculation of the molecular composition of the resulting solution has, therefore, been omitted.

The ratio evidently corresponds to the reaction between 20 molecules $\mathrm{NaCy}$ and 6 molecules $\mathrm{ZnO}$, and the equation corresponding may be stated:

$$
\begin{aligned}
& 20 \mathrm{NaCy}+6 \mathrm{ZnO}+4 \mathrm{H}_{2} \mathrm{O}=5 \mathrm{Na}_{2} \mathrm{ZnCy}_{4}+\mathrm{Na}_{2} \mathrm{ZnO}_{2} \mathrm{O}_{2} .8 \mathrm{NaOH} \text {. } \\
& \text { This Journal, 2, 27. }
\end{aligned}
$$


ACTION OF COLD DILUTE (DECINORMAL) SOLUTIONS OF POTASSIUM HYDROXIDE UPON ZINC CYANIDE. ${ }^{1}$

The potassium hydroxide used was freed from carbonate, and the zinc cyanide was nearly normal and recently prepared.

From the experimental results which are tabulated in Table $\mathrm{V}$ it appears that zinc cyanide is dissolved readily and permanently by a decinormal solution of potassium hydroxide, up to the point corresponding to the proportion $2 \mathrm{KOH}+\mathrm{ZnCy}_{2}$; further additions dissolve less readily up to the point of saturation, which occurs when the number of molecules of zinc cyanide added approaches that of the potassium hydroxide; any zinc cyanide in excess of the proportion $\mathrm{ZnCy}_{2}+\mathrm{KOH}$ is unacted upon. If the solution has been thus saturated with zinc cyanide, or if the amount dissolved exceeds the proportion I molecule $\mathrm{ZnCy}_{2}+2$ molecules $\mathrm{KOH}$, then a precipitate soon begins to form and continues to fall out for some time, or until equilibrium is reached; this precipitate consists of pure zinc oxide, which is deposited in a finely divided form and adheres closely to the sides of the containing vessel.

If the mixture is warmed, the precipitation is hastened and equilibrium is soon reached. In any case, the final solution approaches the composition $\mathrm{K}_{2} \mathrm{ZnCy}_{4}$, but in cases where the zinc cyanide is but slightly in excess of the proportion $\mathrm{ZnCy}_{2}+2 \mathrm{KOH}$, an appreciable amount of potassium zincate seems to remain in solution unless heat is applied, when it soon decomposes with deposition of zinc oxide.

The complete reaction, when zinc cyanide is in excess and after equilibrium has been attained, approaches that represented by the equation $2 \mathrm{KOH}+2 \mathrm{ZnCy}_{2}=\mathrm{K}_{2} \mathrm{ZnCy}_{4}+\mathrm{ZnO}+\mathrm{H}_{2} \mathrm{O}$. If, however, the potassium hydroxide is in excess, the reaction appears to be ${ }_{4} \mathrm{KOH}+2 \mathrm{ZnCy}_{2}=\mathrm{K}_{2} \mathrm{ZnCy}_{4}+\mathrm{K}_{2} \mathrm{ZnO}_{2}+2 \mathrm{H}_{2} \mathrm{O}$. If the proportion of molecules of hydroxide to zinc cyanide lies between $I: I$ and $2: I$, there appears to be a mixed reaction, involving both of the above equations.

The composition assigned by calculation to the various solutions examined, as regards proportion of potassium zinc cyanide and potassium zincate, is verified by the behavior of these solutions on heating, those in which the larger proportions of zincate are indicated depositing the heavier precipitates of zinc oxide.

1 See curves $A$ and $B$. 


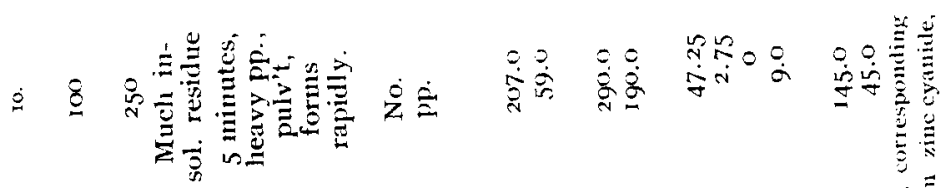

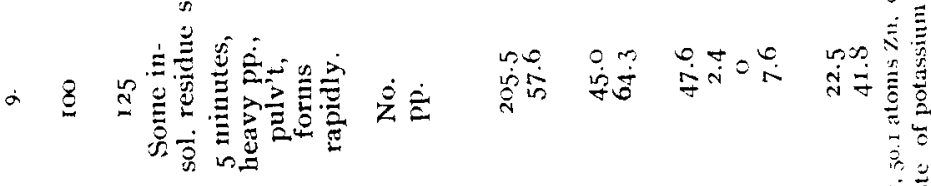

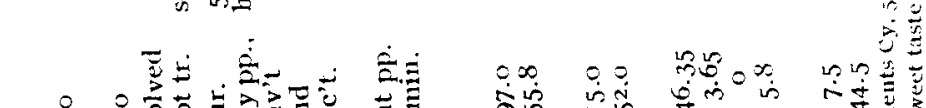

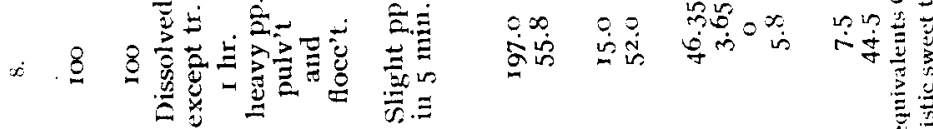

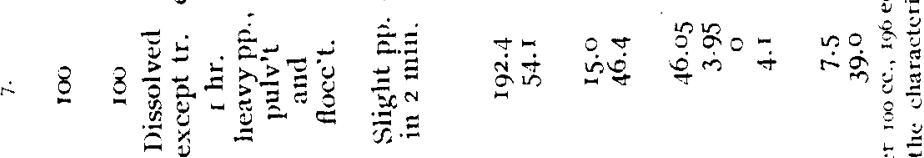

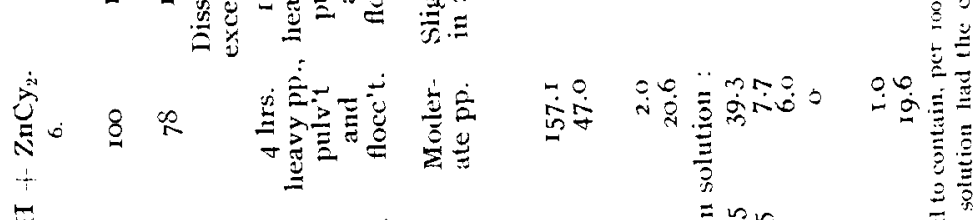

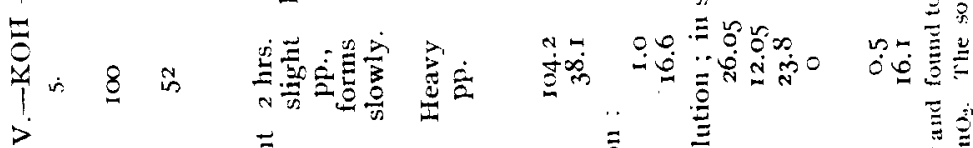

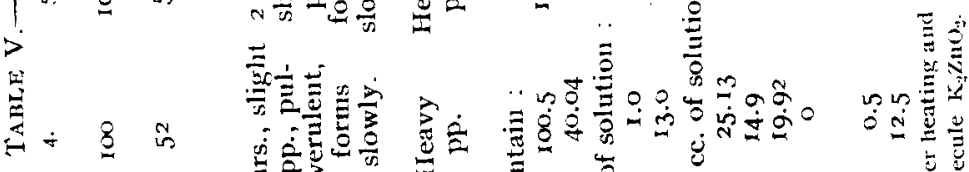
$\{\div 8$ के

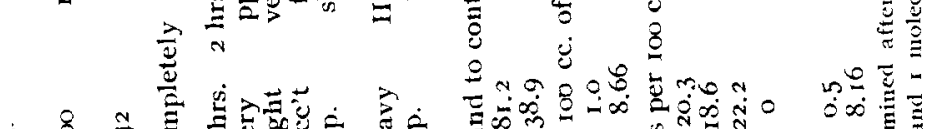

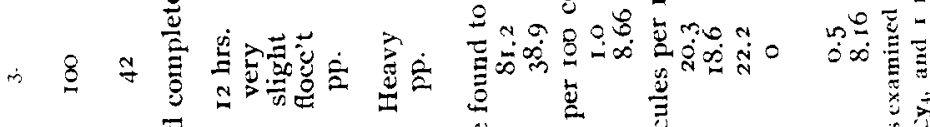

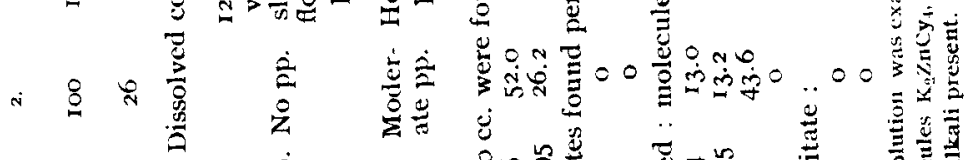

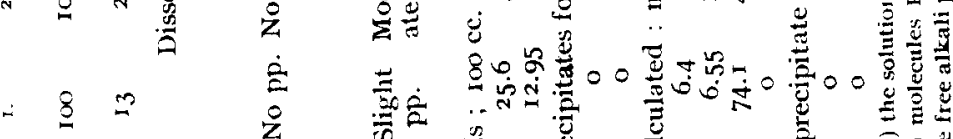

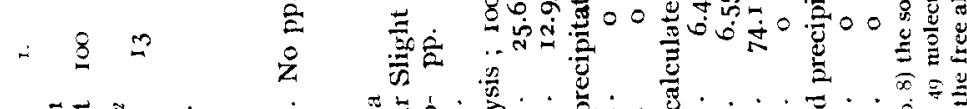

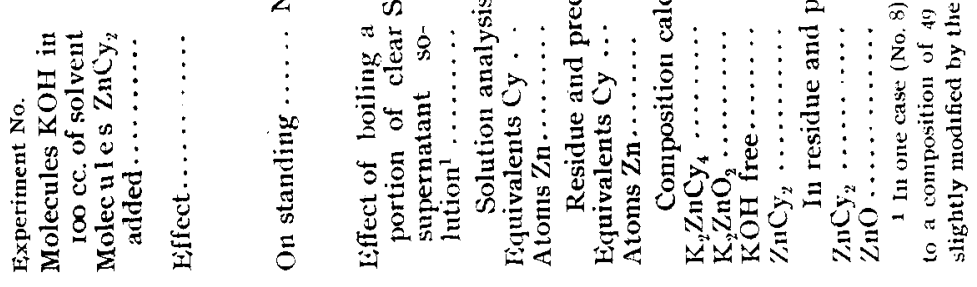


The reaction taking place when the larger proportion of zinc cyanide passes into unstable solution- 1 molecule of zinc cyanide for I molecule of hydroxide of either potassium or sodium as shown in tables V and VI-may possibly be accounted for by the formation (in the latter case) of the unstable compounds $\mathrm{NaZnCy}_{3}{ }^{1}$ and $\mathrm{Na}_{2} \mathrm{Zn}_{2} \mathrm{O}_{3},{ }^{2}$ and possibly $\mathrm{KZnCy}_{3}$ and $\mathrm{K}_{2} \mathrm{Zn}_{2} \mathrm{O}_{8} ;^{\text {; }}$ in the former,

$$
6 \mathrm{NaOH}+6 \mathrm{ZnCy}_{2}={ }_{4} \mathrm{NaZnCy}_{3}+\mathrm{Na}_{2} \mathrm{Zn}_{2} \mathrm{O}_{3}+3 \mathrm{H}_{2} \mathrm{O}
$$

the latter compounds splitting up to form $3 \mathrm{Na}_{2} \mathrm{ZnCy}_{4}+3 \mathrm{ZnO}$. This is suggested as a probable explanation of the instability of the solutions thus formed, the compounds $\mathrm{K}_{2} \mathrm{Zn}_{2} \mathrm{O}_{3}$ and $\mathrm{Na}_{2} \mathrm{Zn}_{2} \mathrm{O}_{3}, \mathrm{H}_{2} \mathrm{O}$ (or $\mathrm{NaHZnO}_{2}$ ) being stated by their discoverers to be decomposed by water, while from the experiments already described it appears that $\mathrm{NaZnCy}_{3}$ is obtained only in concentrated solutions.

The curves appended show more clearly the variation in composition found with addition of varying proportions of zinc cyanide and constant quantities of potassium hydroxide. Curve $A$ indicates the results directly obtained by analysis of solutions and residues, while Curve $B$ shows the molecular proportions of double cyanide, zincate, and other products calculated therefrom.

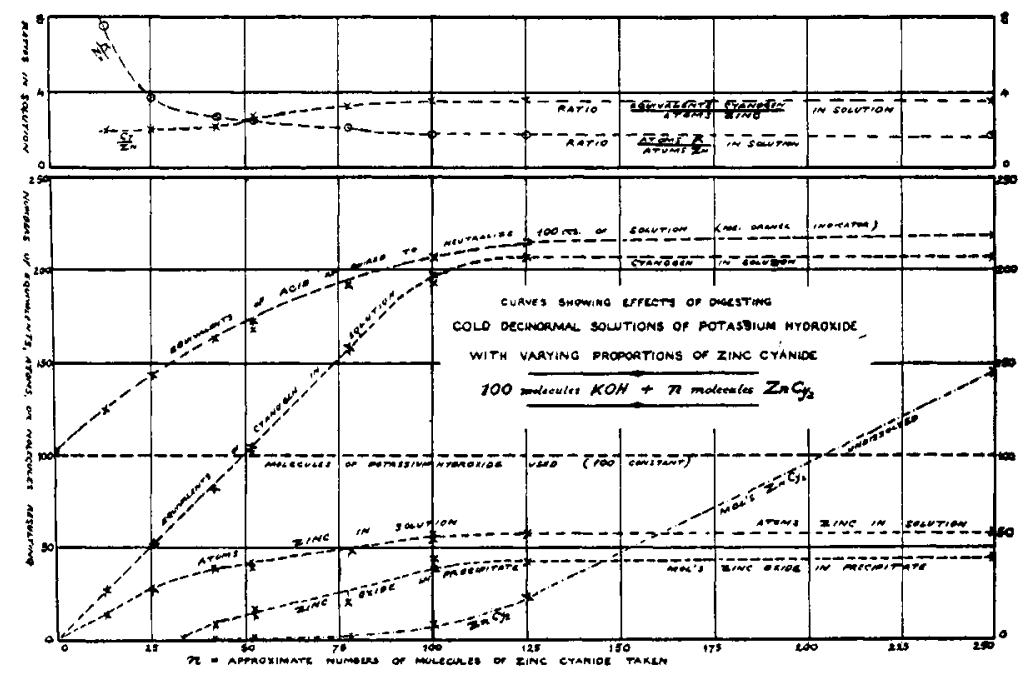

Curve $A$. Fig. I.

1 Rammelsberg: Pogg. Ann.,

2 Comey and Jackson: Am. Chem. J., II, 545 .

a Fremy: Compt. rend., 15, 156. 


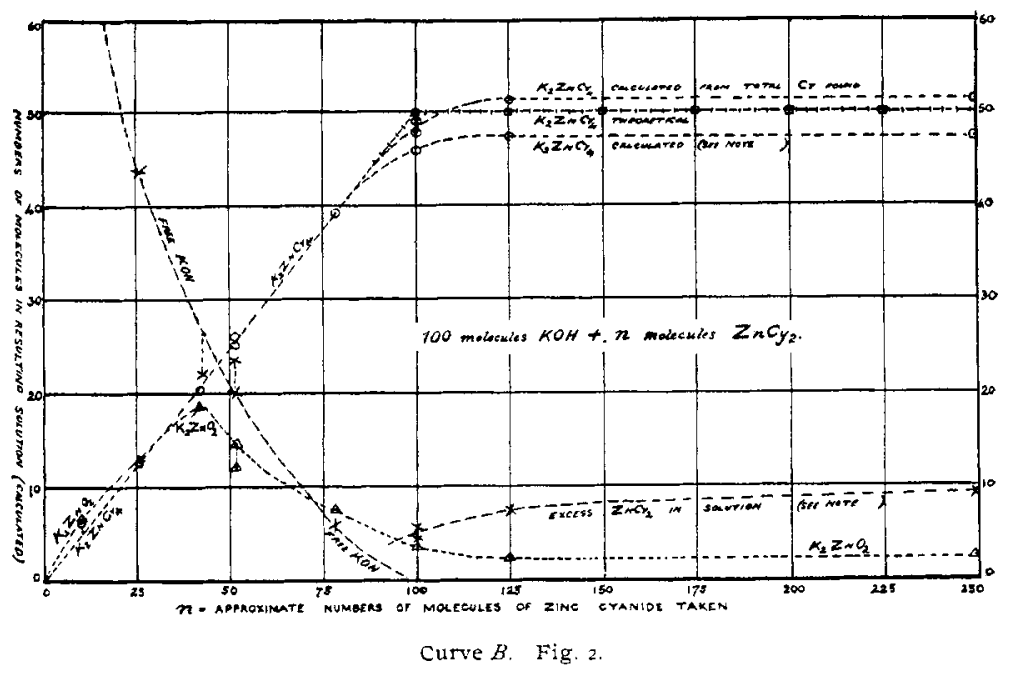

The fact that in some cases, especially when the proportion of zinc cyanide was very large, the amounts of zinc and of cyanogen finally found in the solution were somewhat in excess of those corresponding to the formation of $\mathrm{K}_{2} \mathrm{ZnCy}_{4}$, may be explained either by the dissolving of some $\mathrm{ZnCy}_{2}$ as such, or by its forming a certain proportion of $\mathrm{KZnCy}_{3}$ which remains undecomposed, but the most probable explanation is the formation of a small amount of ammonia in the zinc cyanide, either before or during the experiments, 3 molecules of ammonia having been found to dissolve I molecule of zinc cyanide, when applied in dilute solution.

\section{ACTION OF DILUTE (DECINORMAL) SOLCTIONS OF SODIUM HYDROX-} IDE UPON ZINC CYANIDE.

The general effects on mixing zinc cyanide with sodium hydroxide were similar to those with potassium hydroxide. The zinc cyanide dissolved readily on the first additions, then more slowly until the number of molecules of zinc cyanide dissolved approached that of the sodium hydroxide, when the solution became saturated: on standing, such a saturated solution deposited about half the dissolved zinc as oxide. In the final solution, however, the proportion of cyanogen present to sodium hydroxide taken is smaller than is the case with an equivalent amount of potassium hydroxide, when an excess of zinc cyanide is used, viz., about I80 


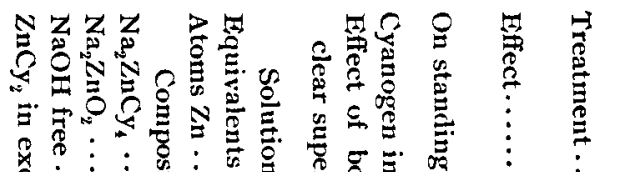

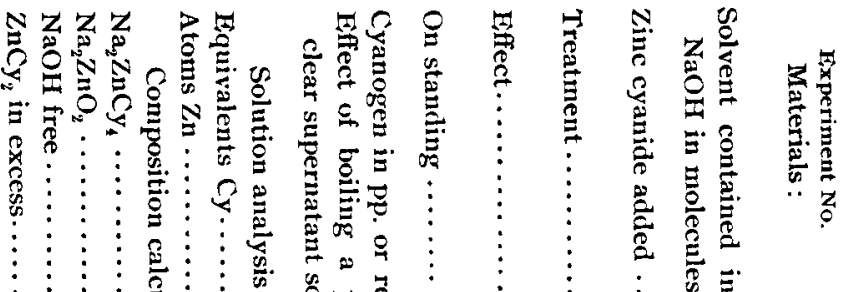

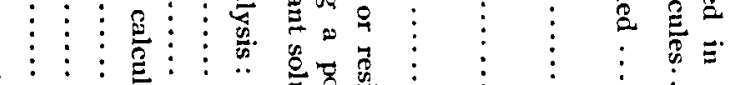

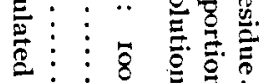

$\overline{8}$

8

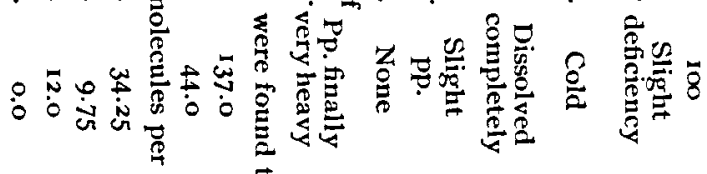

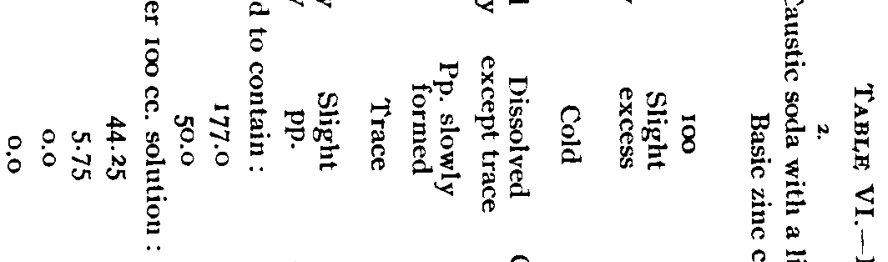

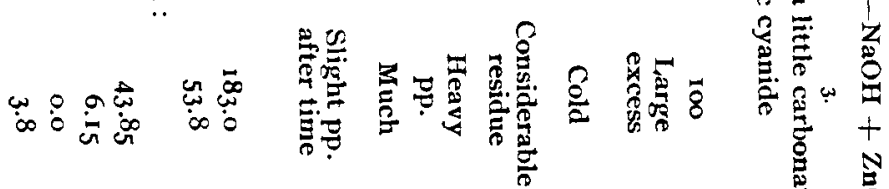

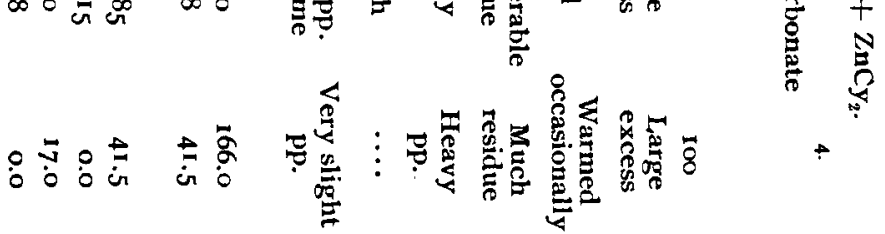

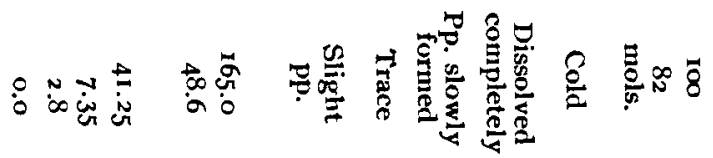

$\stackrel{0}{E}$

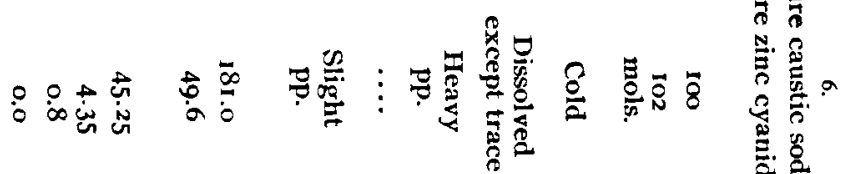

这

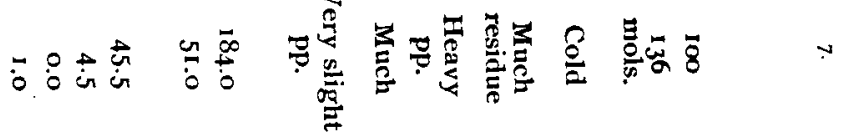


equivalents cyanogen to 100 of soda, as against about 200 cyanogen to IOo of potash.

The extent of precipitation upon heating the clear solutions agrees in a general way with the proportion of zincate calculated when the cyanogen is reckoned as $\mathrm{Na}_{2} \mathrm{ZnCy}_{4}$, but not when it is reckoned as $\mathrm{NaZnCy}_{3}$.

It will be noted that the values for $\mathrm{Na}_{2} \mathrm{ZnCy}_{4}$, etc., in Nos. 5,6 , and 7 fit within $I$ or 2 units of those plotted in Curve $B$ for $\mathrm{K}_{2} \mathrm{ZnCy}_{4}$ on the parallel experiments with $\mathrm{KOH}$. Compare also Table V.

After heating, the solution was examined only in the case of No. 6 , the analysis of which showed I8I equivalents cyanogen and 46 atoms zinc, corresponding to 45.25 molecules $\mathrm{Na}_{2} \mathrm{ZnCy}_{4}$, as before, 0.75 molecule $\mathrm{Na}_{2} \mathrm{ZnO}_{2}$, and 8 molecules $\mathrm{NaOH}$, which would indicate the stability of the compound $\mathrm{Na}_{2} \mathrm{ZnCy}_{4}$, confirmed also by the results of No. 4 , the unstable sodium zincate being almost completely decomposed by the heating.

The length of time of contact in experiments $I$ to 4 was not recorded but was at least three to four days; in Nos. 5 to 7 it was forty-eight hours.

ACIION OF SODIUM CARBONATE SOLUTION ON ZINC CYANIDE.

A solution of sodium carbonate of known strength and volume was mixed with a considerable quantity of basic zinc cyanide. Two such mixtures were made, each was placed in a graduated vessel and water added till the total rolume in each was such that IOO cc. contained 20 milligram-molecules (200 mols) $\mathrm{Na}_{2} \mathrm{CO}_{3}$. These mixtures were left for forty-eight hours. No. I was kept cold, but shaken at intervals. No. 2 was heated to boiling-point for about two minutes at the start, and again after twenty-four hours, and also shaken occasionally. After forty-eight hours zinc and cyanogen were estimated in the clear solutions.

The character of the semi-transparent, gelatinous, zinc cyanide changed soon after being introduced, very rapidly on warming, beconing dead-white and bulky,-resembling zinc carbonate, which was probably formed in part. The residue settled slowly but was very casily filtered off. A little gas was given off from No. 2 after heating. 


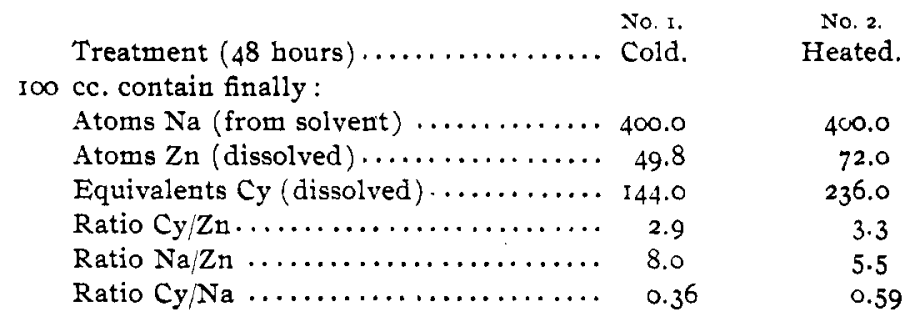

There seems to have been no complete reaction. According as $\mathrm{Na}_{2} \mathrm{ZnCy}_{4}$ or $\mathrm{NaZnCy}_{3}$ were formed (see sodium zinc cyanide above), one would expect a reaction such as illustrated by the equation

or

$$
\mathrm{Na}_{2} \mathrm{CO}_{3}+2 \mathrm{ZnCy}_{2}=\mathrm{Na}_{2} \mathrm{ZnCy}_{4}+\mathrm{ZnCO}_{3}
$$

$$
\mathrm{Na}_{2} \mathrm{CO}_{3}+3 \mathrm{ZnCy}_{2}=2 \mathrm{NaZnCy}_{3}+\mathrm{ZnCO}_{3} \text {, }
$$

as zinc carbonate is evidently one of the products. The latter reaction (forming $\mathrm{NaZnCy}_{3}$ ) is apparently suggested by the ratio of the zinc and cyanogen, but the ratios of both zinc and cyanogen to sodium are so small as to make it certain that much of the sodium carbonate remained undecomposed.

The resulting clear solution acted as a solvent for gold.

SUMMARY OF RESULTS.

When an alkaline solution, containing potassium, zinc and cyanogen, is concentrated, potassium zinc cyanide $\left(\mathrm{K}_{2} \mathrm{ZnCy}_{4}\right)$ readily crystallizes out and can be easily obtained in a state of considerable purity. This salt is also formed in solution when potassium cyanide acts on zinc cyanide or zinc oxide, or when potassium hydroxide acts upon an excess of zinc cyanide, as, when equilibrium is attained, and any zincate formed is decomposed by heating, the atomic ratio of zinc to cyanogen in the solution is almost exactly $I: 4$.

A sodium cyanide solution, saturated with zinc cyanide and concentrated, crystallizes with extreme difficulty to form hydrated crystals of sodium zinc cyanide $\left(\mathrm{NaZnCy}_{3}\right)$ which it seems impossible to obtain pure, and which decompose to some extent on addition of water, precipitating basic zinc cyanide. This salt does not appear to exist in the solution, as the mother-liquor contains zinc and cyanogen in approximately the ratio of $I: 4$. Also when dilute solutions of sodium cyanide act on zinc cyanide or oxide, or sodium hydroxide on an excess of zinc cyanide, the atomic ratio 
of zinc to cyanogen in the resulting solution is approximately $\mathrm{I}: 4$, so that the compound $\mathrm{Na}_{2} \mathrm{ZnCy}_{4}$ is contained both in dilute and concentrated solutions.

The hydroxides of potassium or sodium, in decinormal solution, dissolve very little zinc oxide when agitated with it; the zincate formed is largely decomposed on boiling, depositing zinc oxide, even in the presence of a large proportion of alkali.

Potassium cyanide, in dilute solution, dissolves zinc cyanide in accordance with the equation

$$
2 \mathrm{KCy}+\mathrm{ZnCy}_{2}=\mathrm{K}_{2} \mathrm{ZnCy}_{4} \text {, }
$$

forming a stable solution, little affected by long boiling or by the presence of carbonic acid. In dilute solutions, sodium cyanide appears to follow a similar reaction with zinc cyanide, $2 \mathrm{NaCy}+$ $\mathrm{ZnCy}_{2}=\mathrm{Na}_{2} \mathrm{ZnCy}_{4}$, but on concentrating the solutions the formation of the crystals of a different compound indicates that the reaction $\mathrm{NaCy}+\mathrm{ZnCy}_{2}=\mathrm{NaZnCy}_{3}$ takes place under certain conditions.

Potassium cyanide, in decinormal solution, dissolves small proportions of zinc oxide completely. When the zinc oxide is present in excess, it is dissolved in the proportion of 3 molecules of zinc oxide for Io molecules of potassium cyanide, agreeing with the equation

$$
20 \mathrm{KCy}+6 \mathrm{ZnO}+{ }_{4} \mathrm{H}_{2} \mathrm{O}={ }_{5} \mathrm{~K}_{2} \mathrm{ZnCy}_{4}+\mathrm{K}_{2} \mathrm{ZnO}_{2} .8 \mathrm{KOH},
$$

which may be explained as taking place in two steps,

$$
{ }_{4} \mathrm{KCy}+\mathrm{ZnO}+\mathrm{H}_{2} \mathrm{O}=\mathrm{K}_{2} \mathrm{ZnCy}_{4}+2 \mathrm{KOH},
$$

the potassium hydroxide further reacting,

$$
\mathrm{IOKOH}+\mathrm{ZnO}=\mathrm{K}_{2} \mathrm{ZnO}_{2} .8 \mathrm{KOH}+\mathrm{H}_{2} \mathrm{O} \text {. }
$$

On boiling the solution of mixed double cyanide and zincate, the latter is partially decomposed with precipitation of zinc oxide.

With dilute solutions of sodium cyanide, the effects upon zinc cyanide are precisely similar to those observed with potassium cyanide under similar conditions.

Dilute solutions of potassium hydroxide dissolve zinc cyanide. If the zinc cyanide is in less than the proportion corresponding to $\mathrm{ZnCy}_{2}+2 \mathrm{KOH}$, it is dissolved completely and permanently: ${ }_{4} \mathrm{KOH}+2 \mathrm{ZnCy}_{2}=\mathrm{K}_{2} \mathrm{ZnCy}_{4}+\mathrm{K}_{2} \mathrm{ZnO}_{2}+2 \mathrm{H}_{2} \mathrm{O}$,

although upon heating the solution most of the zincate is decomposed with precipitation of zinc oxide, leaving free alkali in solution. Zinc cyanide is also completely dissolved in proportions 
up to that of $\mathrm{ZnCy}_{2}+\mathrm{KOH}$, but a precipitate of zinc oxide begins shortly to fall out. Any zinc cyanide in excess of the last proportion stated is unaffected by the solvent.

When the zinc cyanide corresponds to, or is in excess of, the proportion of I molecule to I of hydroxide, it is dissolved in that proportion, but one-half of the zinc separates out as oxide, the separation beginning soon after solution, and going on slowly. The complete reaction, with an excess of zinc cyanide, and after equilibrium has been attained by the separation of oxide, agrees with the equation

$$
2 \mathrm{KOH}+2 \mathrm{ZnCy}_{2}=\mathrm{K}_{2} \mathrm{ZnCy}_{4}+\mathrm{ZnO}+\mathrm{H}_{2} \mathrm{O} \text {. }
$$

When a very large excess of zinc cyanide had been added, the zinc and cyanogen in solution sometimes slightly exceeded the proportions indicated by this equation, probably owing to the development of a little ammonia by the decomposition of zinc cyanide before or during the experiment.

With sodium hydroxide and zinc cyanide the general effects observed were precisely similar to those just described, but rather less of the zinc cyanide was dissolved in the cold than would correspond to a reaction exactly parallel to that with potassium hydroxide. On heating the solution, however, a little more zinc oxide separated, and the proportion of zinc and cyanogen in solution then agreed closely with the formula $\mathrm{Na}_{2} \mathrm{ZnCy}_{4}$.

The solution of so large a proportion of zinc cyanide by the caustic alkalies (I molecule for each molecule of hydroxide), when first brought together, is somewhat difficult of explanation. It seems most probable that some compounds, richer in zinc than the salts $\mathrm{Na}_{2} \mathrm{ZnCy}_{4}$ and $\mathrm{Na}_{2} \mathrm{ZnO}_{2}$, are temporarily formed, e. g., by some such reaction as the following,

$$
6 \mathrm{NaOH}+6 \mathrm{ZnCy}_{2}={ }_{4} \mathrm{NaZnCy}_{3}+\mathrm{Na}_{2} \mathrm{Zn}_{2} \mathrm{O}_{3}+3 \mathrm{H}_{2} \mathrm{O} \text {, }
$$
which, being unstable in dilute solution, soon break up;

$$
{ }_{4} \mathrm{NaZnCy}_{3}+\mathrm{Na}_{2} \mathrm{Zn}_{2} \mathrm{O}_{3}={ }_{3} \mathrm{Na}_{2} \mathrm{ZnCy}_{4}+3 \mathrm{ZnO} \text {, }
$$

similar reactions taking place with the potassium compounds.

Although the potassium zinc cyanide, $\mathrm{K}_{2} \mathrm{ZnCy}_{4}$, is exceedingly stable at very varying temperatures and degrees of dilution, and crystallizes readily ont of impure and strongly alkaline solutions, still the reaction

$$
\mathrm{K}_{2} \mathrm{ZnCy}_{4}+2 \mathrm{KOH}=\mathrm{K}_{2} \mathrm{ZnO}_{2}+{ }_{4} \mathrm{KCy}+\mathrm{H}_{2} \mathrm{O} \text {, }
$$

or a similar one, appears to take place, probably to a limited $\mathrm{ex}$ - 
tent, when the double cyanide is mixed with potassium hydroxide in solution, for the gold-dissolving power of a double cyanide solution is considerably increased by addition of caustic alkali, the increment of solvent power decreasing for successive equal arditions of alkali.

Several other reactions have been suggested as taking place between some of the substances investigated, but no experimental verification has been found for those investigated: for instance, the equation $\mathrm{K}_{2} \mathrm{ZnCy}_{4}+2 \mathrm{KOH}=\mathrm{Zn}(\mathrm{OH})_{2}+4 \mathrm{KCy}$ is contrary to all observed facts.

\section{THE ALKALOIDS OF ADLUMIA CIRRHOSA.}

BY J. O. SCHLOTTERBECK AND H. C. WATKLNS

Received March 31, 1903.

[SECOND PAPER.]

In a previous paper," "Adlumia Cirrhosa, a New Protopinebearing Plant," the preliminary experiments upon the root of the first year's plant of this biennial were reported. Of the dried root only about roo grams were available and it was treated as follows: It was first moistened with dilute ammonia water for the purpose of liberating the alkaloids from their combinations with acids. To avoid any possible change in the nature of the constituents, the powder was dried at room temperature by spreading out in thin layers in a room in which there was good circulation of air. The drug was now exhausted with chloroform in a Soxhlet apparatus since most free alkaloids are easily soluble in this solvent. The chloroform was recovered from the solution by distillation and the stiff, waxy residue then repeatedly digested with hot, very dilute acetic acid until all alkaloidal matter had been extracted. The combined acid aqueous extracts were concentrated, cooled, filtered and precipitated with ammonia water, being careful to avoid a great excess. The curdy precipitate was thoroughly washed on a filter, redissolved in dilute acetic acid, placed in a separator, made alkaline with ammonia and shaken out with ether. Solution of the alkaloid was almost instantaneous but only temporary. The ethereal liquid was passed through a tuft of cotton into a wide-mouthed flask and set aside. In a very short time 